\title{
Sensitivity of Land Surface Simulations to Model Physics, Land Characteristics, and Forcings, at Four CEOP Sites
}

\author{
Hiroko KATO
}

Hydrological Sciences Branch, Code 614.3, NASA Goddard Space Flight Center, Greenbelt, MD 20771, USA Earth System Science Interdisciplinary Center, University of Maryland, 2207 Computer and Space Sciences Building (\#224) College Park, MD 20742-2465, USA

\section{Matthew RODELL}

Hydrological Sciences Branch, Code 614.3, NASA Goddard Space Flight Center, Greenbelt, MD 20771, USA

\section{Frank BEYRICH}

Deutscher Wetterdienst (DWD), Meteorologisches Observatorium Lindenberg-Richard Aßmann Observatorium, Am Observatorium 12, D-15848 Tauche-OT Lindenberg Germany

\section{Helen CLEUGH, Eva van GORSEL}

CSIRO Marine and Atmospheric Research, GPO Box 1666, ACT Australia 2601

\section{Huizhi LIU}

Institute of Atmospheric Physics, Chinese Academy of Sciences Beijing 100029, China

and

Tilden P. MEYERS

Atmospheric Turbulence and Diffusion Division 456 S. Illinois Ave. Oak Ridge, TN 37830, USA

(Manuscript received 18 February 2006, in final form 26 October 2006)

\begin{abstract}
Numerical land surface models (LSMs) are abundant and in many cases highly sophisticated, yet their output has not converged towards a consensus depiction of reality. Addressing this matter is complicated by the huge number of possible combinations of input land characteristics, forcings, and physics packages available. The Global Land Data Assimilation System (GLDAS) and its sister project the Land Information System (LIS) have made it straightforward to test a variety of configurations with multiple LSMs. In order to compare the impacts of the choice of LSM, land cover, soil, and elevation information,
\end{abstract}

Corresponding author: Matt Rodell, Hydrological

Sciences Branch, Code 614.3, NASA Goddard

Space Flight Center, Greenbelt, MD 20771, USA.

Email: Matthew.Rodell@nasa.gov

(C) 2007, Meteorological Society of Japan 
and precipitation and downward radiation forcing datasets on simulated evapotranspiration, sensible heat flux, and top layer soil moisture, a set of experiments was designed which made use of high quality, physically coherent, 1-year datasets from four reference sites of the Coordinated Enhanced Observing Period (CEOP) initiative. As in previous studies, it was shown that the LSM itself is generally the most important factor governing output. Beyond that, evapotranspiration seems to be most sensitive to precipitation, land cover, and radiation (in that order); sensible heat flux is most sensitive to radiation, precipitation, and land cover; and soil moisture is most sensitive to precipitation, soil, and land cover. Various seasonal and model specific dependencies and other caveats are discussed. Output fields were also compared with observations in order to test whether the LSMs are capable of simulating an observed reality given a plausible set of inputs. In general, that potential was fair for evapotranspiration, good for sensible heat flux but problematic given its strong sensitivity to the inputs, and poor for soil moisture. The results emphasize that improving the LSMs themselves, and not just the inputs, will be essential if we hope to model land surface water and energy processes accurately.

\section{Introduction}

Numerical land surface models (LSMs) have become increasingly numerous and complex since Manabe (1969) introduced his bucket hydrology model. At the same time, land property and forcing fields which can be used as inputs to LSMs have become more abundant and highly resolved, and in some cases more reliable owing to remote sensing technologies. Despite the sophistication of modern LSMs and omniscience of new input datasets, model generated surface state and flux fields continue to exhibit significant variability, largely because of the huge number of possible combinations of land characteristics datasets, forcings, and physics packages.

The Global Land Data Assimilation System (GLDAS) and its sister project the Land Information System (LIS) have made it straightforward to execute simulations with multiple land surface and meteorological forcing datasets and several LSMs, through a user-friendly software interface. The desire to test the many possible configurations in an intelligent manner motivated this study. A set of experiments was designed to help rank the impact of the user's land property, forcing, and LSM decisions on simulated evapotranspiration, sensible heat flux, and soil moisture at four reference sites of the Coordinated Enhanced Observing Period (CEOP) initiative where in situ land surface and hydrometeorological data were available. The three simulated fields were also compared with observations. The goal here was not to validate, but rather to determine whether reality is within the range of possible outcomes from a set of reasonable configurations. Furthermore, forcing fields contain inconsistencies, caused by periodic changes in the observing systems that contribute and the analysis systems that digest the data. Knowing the extent to which forcing affects output is important for evaluating consistency in any long term simulation. This, in turn, is critical for gauging uncertainty in apparent trends and for assessing background conditions for land data assimilation. This study also emphasizes the value in refining the land parameter and forcing datasets themselves.

\section{Background}

\subsection{Previous studies}

It is well known that LSM physics, land characteristics, and forcings can have significant impacts on simulated results. The Project for Intercomparison of Land-Surface Schemes (PILPS; Henderson-Sellers et al. 1995; Pitman et al. 1999a) promotes enhanced documentation, comparison, and validation of land surface schemes through community participation. PILPS has demonstrated that among LSMs forced by identical meteorological data and values for commonly named parameters, in specific geographic locations, significant scatter exists in the partitioning of precipitation into evapotranspiration and runoff (e.g., Chen et al. 1997; Liang et al. 1998; Wood et al. 1998), and that calibrating model parameters improves skill (Lettenmaier et al. 1996). The differences among LSM outputs are caused by a combination of different model structure, complexity, economy of physics, and usage and tuning of model parameters. The effective definitions of 
various model parameters are often inconsistent among LSMs (Xia et al. 2002). To assess sources of scatter among the PILPS LSMs, Liang and Guo (2003) evaluated the sensitivities of evapotranspiration, total runoff, sensible heat flux, and total column soil moisture modeled by ten LSMs to perturbation of three soil parameters and two vegetation parameters. Their results suggested that the soil parameters have more influence than the vegetation parameters on surface water and energy partitioning. The Global Soil Wetness Project (GSWP; Dirmeyer et al. 1999) also revealed significant scatter among LSMs at the global scale despite a common set of land property and forcing fields. The second phase of GSWP, which is ongoing, includes a series of sensitivity studies to assess model response to changes in surface parameters and forcing (IGPO 2002). Other than being performed on a much smaller scale, this study differs from GSWP2 in the following ways: 1) the focus is on four CEOP reference sites; 2) in situ observations are used to set the control land attribute and forcing inputs and to evaluate the results; 3 ) the same driver, compiler, and Linux based server are used to run all three LSMs, which is important for ensuring consistent results; and 4) sensitivity to soil and elevation datasets is considered.

A number of studies have evaluated LSM sensitivities. Methods of sensitivity analysis and their strengths and weaknesses are reviewed in Bastidas et al. (1999) and Liang and Guo (2003). The methods fall into to two categories: one-at-a-time and multiple parameter perturbation. The investigation described here used a variant of the one-at-a-time approach in which entire land characteristics fields, to which many parameters are indexed, were replaced. Pitman (1994) used the one-at-a-time approach to assess the sensitivity of sensible heat flux, latent heat flux, temperature, soil moisture, and runoff to variations in the Biosphere Atmosphere Transfer Scheme (BATS) model's parameters in temperate grassland, tropical forest, and dry coniferous forest. He concluded that different variables have different degrees of sensitivity, and that sensitivities change according to climate, soil water availability, and vegetation type, as well as the magnitude and sign of the parameter change. The disadvantage of the one-at-a-time approach is that feedbacks within the models often cause non-linear responses to the parameter perturbations.

Bastidas et al. (1999) used the multicriteria method of Gupta et al. (1998, 1999) to evaluate sensitivity of modeled sensible heat, latent heat, and ground temperature to variations in multiple BATS parameters at two climatologically contrasting sites in Arizona, USA, and the southern Great Plains, USA. The method searches for sets of parameters that minimize the error across multiple model responses (simulated fluxes and states). The sets of solutions (called Pareto sets) account for interactions or trade-offs among the parameters, and they are ranked based on the model responses. Bastidas et al. (1999) showed that BATS was most sensitive to the parameters associated with the key physical processes under the given climate and vegetation type. This approach is effective in assessing multiobjective (more than one objective function) parameter sensitivity, and it has been widely applied for calibrating LSMs (e.g., Xia et al. 2002; Crow et al. 2003; Xia et al. 2004; Hogue et al. 2005).

\subsection{GLDAS and LIS}

GLDAS ingests satellite- and ground-based observational products as data for parameterizing, forcing, and constraining a suite of offline (uncoupled) land surface models, in order to generate optimal fields of land surface states and fluxes (Rodell et al. 2004). The project has resulted in a massive archive of modeled and observed, global, surface meteorological data, land characteristics maps, and output, which support several current and proposed weather and climate prediction, water resources, and water cycle investigations.

LIS (Kumar et al. 2006) streamlined and parallelized the GLDAS software, and is able to drive an ensemble of land surface models including Noah, the Common Land Model (CLM), the Variable Infiltration Capacity model (VIC), Mosaic, the Simple Biosphere (SiB) and Simple $\mathrm{SiB}$ models, and the Catchment LSM. LIS can run on points, regions or the globe at spatial resolutions from 1 degree down to $1 \mathrm{~km}$. LIS is fully modularized and compliant with Earth System Modeling Framework (ESMF; Hill et al. 2004) and Assistance for Land surface Modeling Activities (ALMA 2002) standards, mak- 
ing it an ideal platform for developing innovative modeling and assimilation capabilities.

\subsection{Land Surface Models}

This investigation focuses on three LSMs: Noah, Mosaic, and CLM. These were chosen because of their inclusion in LIS. They are also well known and well tested. Noah and CLM are the land modules of the operational prediction systems of the US National Oceanographic and Atmospheric Administration (NOAA) and US National Center for Atmospheric Research (NCAR), and Mosaic is a precursor of the land module of NASA's Global Modeling and Assimilation Office's (GMAO) prediction system.

\section{a. Noah}

The Noah LSM (Chen et al. 1996; Koren et al. 1999) was developed beginning in 1993 through a collaboration of investigators from public and private institutions, spearheaded by the National Centers for Environmental Prediction (NCEP). Noah is a stand-alone, 1D column model which can be executed in either coupled or uncoupled mode. Noah simulates soil moisture (both liquid and frozen), soil temperature, skin temperature, snow depth, snow water equivalent, canopy water content, and the land surface energy and water fluxes. The model applies finite-difference spatial discretization methods and a Crank-Nicholson time-integration scheme to numerically integrate the governing equations of the physical processes of the soil-vegetation-snowpack medium. Noah has been used operationally in NCEP models since 1996, and it continues to benefit from a steady progression of improvements (Betts et al. 1997; Ek et al. 2003).

\section{b. Mosaic}

Mosaic (Koster and Suarez 1996) is a well established and theoretically sound LSM, as demonstrated by its performance in PILPS and GSWP experiments. Mosaic's physics and surface flux calculations are similar to the $\mathrm{SiB}$ LSM (Sellers et al. 1986). It is a stand-alone, 1-D column model that can be run both uncoupled and coupled to the atmospheric column. Mosaic was the first to treat subgrid scale variability by dividing each model grid cell into a mosaic of tiles (after Avissar and Pielke 1989) based on the distribution of vegetation types within the cell. This capability is now available in the LIS interface for all the models it drives, although it was not utilized in the experiments described here.

\section{c. Common Land Model}

CLM (Dai et al. 2003) was conceived at the 1998 National Center for Atmospheric Research (NCAR) Climate System Model (CSM) meeting, and it was subsequently developed by an open collaboration of scientists. CLM includes superior components from each of three contributing models: the NCAR Land Surface Model (Bonan 1998), the BiosphereAtmosphere Transfer Scheme (Dickinson et al. 1993), and the LSM of the Institute of Atmospheric Physics of the Chinese Academy of Sciences (Dai and Zeng 1997). The model applies finite-difference spatial discretization methods and a fully implicit time-integration scheme to numerically integrate the governing equations. CLM can be run as a stand-alone, 1D column model. It is also the land model for NCAR's coupled Community Climate System Model (CCSM). CLM continues to evolve, but only proven and well-tested physical parameterizations and numerical schemes are installed in the official version of the code. LIS currently uses CLM version 2.0.

\subsection{The Coordinated Enhanced Observing Period (CEOP)}

CEOP is an initiative of the Global Energy and Water Cycle Experiment (GEWEX) which began in 2001 with the goal of bringing together in situ, satellite, and model data during a period of intensive observations to support water and energy cycle, monsoon system, and climate prediction studies. CEOP centralizes and distributes data from more than thirty field measurement stations, known as reference sites, which are well distributed over the globe. Surface meteorological and hydrological observations are collected at each site. Recently, soil and vegetation characteristics were identified at the reference sites to enhance modeling studies. In particular, characteristics such as elevation, soil texture, and vegetation cover are basic and important inputs to GLDAS.

\section{Data}

When performing regional to global scale simulations, the standard GLDAS forcing is a combination of atmospheric data assimilation 
system output and satellite observation based products. Standard land characteristics are derived from the few available global vegetation, soils, and elevation products. In this study, the simulations were local, and the control inputs were observations from the four reference sites described below. In each experiment, one standard GLDAS input dataset replaced a control input dataset, with the overall goal of gauging model sensitivity to a probable range of potential input land properties and forcing time series.

\subsection{CEOP reference site data}

Data from four CEOP reference sites drove this investigation. These sites, Lindenberg, Tongyu, Bondville, and Tumbarumba, were chosen based on data availability and a desire to study multiple geographic and climatological settings. Site measurements include air temperature, humidity, wind speed and direction, pressure, precipitation, incoming and outgoing radiation, turbulent fluxes (latent and sensible heat), and soil moisture. In addition, reference site managers reported the predominant vegetation type using the University of Maryland 13 class system, the soil type or percentages of sand, silt, and clay, and the elevation. The four reference sites are described next.

\section{a. Lindenberg}

The Meteorological Observatory Lindenberg is a component of the Germany's national meteorological service. The surface, soil, and flux measurements used in this study were collected at the Falkenberg Boundary Layer Field Site $\left(52.167^{\circ} \mathrm{N}, 14.124^{\circ} \mathrm{E}\right.$, elevation $\left.73 \mathrm{~m}\right)$, originally installed in 1998. Lindenberg experiences moderate mid-latitude climate conditions with both marine and continental influences. Monthly mean temperature varies between about $1.2^{\circ} \mathrm{C}$ (January) and $17.9^{\circ} \mathrm{C}$ (July), and total annual precipitation averages $563 \mathrm{~mm}$. Precipitation peaks in the summer and exhibits a secondary maximum in December with minima in February and October. The Falkenberg field site is a flat meadow of $150 \mathrm{~m}$ by $250 \mathrm{~m}$ covered by short grass (managed regularly so that the vegetation height is always less than $20 \mathrm{~cm}$ ). This area is surrounded by grassland and agricultural fields in the immediate vicinity, with a small village about $600 \mathrm{~m}$ to the southeast and a small, heterogeneous forest area slightly more than $1 \mathrm{~km}$ to the west northwest. Pale sands and brown soils cover a layer of loam, which can be typically found at about $50 \mathrm{~cm}$ to $80 \mathrm{~cm}$ below the surface.

Flux measurements are made using omnidirectional sonic anemometer-thermometers. Fast-response infrared hygrometers were added to these in spring 2003 for the direct measurement of latent heat flux using the eddycovariance method. Soil moisture is measured using time domain reflectometry at $8,15,30$, 45, 60, and $90 \mathrm{~cm}$ depths. Meteorological data are measured from a $10 \mathrm{~m}$ lattice mast. Radiation measurements are collected at about $120 \mathrm{~m}$ south of the mast. Soil moisture is measured west of the radiation measurements. Flux measurement instruments are located near the $10 \mathrm{~m}$ mast in the eastern part of the meadow and at the western edge of the field site, providing flux data representative of the grassland area for both westerly and easterly winds. More detailed description of the site can be found in the CEOP dataset documentation available at http://data.eol.ucar.edu/datafile/ nph-get/76.120/BALTEX_Lindenberg_ALL.pdf.

\section{b. Tongyu}

The Tongyu observation site consists of two stations that are maintained by the Institute of Physics of Jinlin province, Chinese Academy of Sciences. The stations are $5 \mathrm{~km}$ apart and located at Tongyu, Northeastern China $\left(44.416^{\circ} \mathrm{N}, 122.867^{\circ} \mathrm{E}\right.$, elevation $\left.184 \mathrm{~m}\right)$, on a flat Songliao plain. The area is semi-arid with a mean annual precipitation of $388 \mathrm{~mm}$ in Tongyu County, about $30 \mathrm{~km}$ northeast of the site. Precipitation totals are highly variable from year to year. Approximately $80 \%$ of precipitation occurs between May and September. The mean annual air temperature in Tongyu County is $5.70^{\circ} \mathrm{C}$. There is one grassland station and one cropland station. Only the cropland station data was used in this study. The main crops within $1 \mathrm{~km}$ of the measurement location are corn and sunflower, which achieve a height of $2 \mathrm{~m}$ during the growing season. The ground is partly bare in the winter. Soils are described as sandy, salty alkaline, black humus, or meadow soil.

Turbulence measurements are taken by the ultra-sonic anemometer/thermometer at $3.5 \mathrm{~m}$ and an open-path infrared gas analyzer. Volu- 
metric soil moisture content is measured using time domain reflectometry at $5,10,20,40,80$ and $160 \mathrm{~cm}$. Meteorological measurements are made from a 20-meter tower. Radiation measurements are made at $3 \mathrm{~m}$ height, $20 \mathrm{~m}$ away from the tower. More detailed description of the site can be found in the CEOP dataset documentation available at http://www.eol.ucar .edu/projects/ceop/dm/documents/rsite/.

\section{c. Bondville}

The Bondville site is a part of the NOAA GEWEX air SURFace eXchange sites (SURFX) that are sponsored by the GAPP (GEWEX Americas Prediction Project) and maintained by NOAA Atmospheric Turbulence and Diffusion Division. It is located near Champaign, Illinois, USA, on Reifsteck Farm $\left(40.006^{\circ} \mathrm{N}\right.$, $88.290^{\circ} \mathrm{W}$, elevation $216 \mathrm{~m}$ ). The climate regime is temperate-continental. Annual precipitation averages $582 \mathrm{~mm}$ and the mean annual temperature is $11.5^{\circ} \mathrm{C}$. Since 1986 the vegetation has alternated between corn and soybeans, with maximum canopy height ranges of 2.6$3.0 \mathrm{~m}$ and $0.7-1.0 \mathrm{~m}$, respectively. Soils are moderately well drained silt loams.

Flux measurements are taken by ultrasonic anemometers at $10 \mathrm{~m}$ height. An open path infrared gas analyzer monitors latent heat flux. Soil moisture is measured using Delta-T Profiler capacitance probes at depths of $10,20,30$, 40,60 , and $100 \mathrm{~cm}$.

\section{d. Tumbarumba}

The Tumbarumba flux station was established in March 2000 and is managed by Australia's Commonwealth Scientific and Industrial Research Organisation's (CSIRO) Division of Marine and Atmospheric Research. It is situated in southeast Australia $\left(35.656^{\circ} \mathrm{S}\right.$ $148.152^{\circ} \mathrm{E}$, elevation $1200 \mathrm{~m}$ ) within the Bago State Forest, which is a native forest of 50,000 ha that has been managed for wood production for over 100 years. It is a moderately open (leaf area index $(L A I) \sim 2.4$, wet sclerophyll forest. The dominant species are Eucalyptus delegatensis and E. dalrympleana of mixed ages ranging up to 90 years, with a height of about $40 \mathrm{~m}$. The climate is wet temperate, with typical annual rainfall of $1000 \mathrm{~mm}$ and temperatures that range between $-10^{\circ}$ and $30^{\circ} \mathrm{C}$. Soils are characterized as deep loamy clays.

Flux measurements are made using the open-path eddy flux technique. Soil moisture content is measured using time domain reflectometry within depth ranges of $0-15,15-30$, $30-45,45-60,60-75,75-90,90-105,105-$ $120 \mathrm{~cm}$. The instrument mast is $70 \mathrm{~m}$ tall. Full details are provided in Leuning et al. (2005).

\subsection{Standard GLDAS land characteristics}

GLDAS uses a static, $1 \mathrm{~km}$ resolution, global land cover classification dataset which was produced at the University of Maryland (UMD; Hansen et al. 2000). It is based on observations from the Advanced Very High Resolution Radiometer (AVHRR) aboard the NOAA-15 satellite. The soil information used in GLDAS was derived from the 5 arc minute resolution global soils dataset of Reynolds et al. (2000). Porosity and the percentages of sand, silt, and clay were horizontally re-sampled to the appropriate grid and linearly interpolated to the modelspecific soil depths from the original $0-30 \mathrm{~cm}$ and $30-100 \mathrm{~cm}$ depths. GLDAS uses a global 30 arc second resolution topographic map (GTOPO30; Gesch et al. 1999) as its standard, which is upscaled as necessary. GLDAS corrects the forcing temperature, pressure, humidity, and longwave radiation based on the difference between the GTOPO30 elevation definition and that of the atmospheric model which created the forcing data, following Cosgrove et al. (2003).

\subsection{Standard GLDAS forcing}

The Global Data Assimilation System (GDAS) is the operational, global atmospheric analysis system of NCEP (Derber et al. 1991). It assimilates a variety of conventional data (radiosonde, buoy, ship, and airborne) and satellitederived observations, using a four-dimensional multivariate approach. Analyses are produced for four synoptic hours: 00, 06, 12, and 18 UTC. GLDAS uses these and the 03-h and 06-h background forecasts, as necessary.

To force the models, GLDAS overwrites the GDAS precipitation and downward solar radiation fields with observation based products. One is based on the NOAA Climate Prediction Center's operational, global, $2.5^{\circ}$ resolution, 5day Merged Analysis of Precipitation (CMAP), which is a blending of satellite (IR and microwave) and gauge observations (Xie and Arkin 1997). GLDAS uses GDAS precipitation analyses to disaggregate the CMAP fields spatially 
Table 1. Input land characteristics based on station observations (control; normal font) and the GLDAS standard (experimental; italics). Columns from left to right are the CEOP reference site name, elevation [m], UMD land cover class, percentages of sand and clay in the shallow subsurface, and Zobler and USDA soil classes.

\begin{tabular}{|c|c|c|c|c|c|c|}
\hline Site Name & Elev. & Land cover & Sand & Clay & Zobler & USDA \\
\hline Lindenberg & $\begin{array}{l}73 \\
68\end{array}$ & $\begin{array}{l}\text { Grassland } \\
\text { Cropland }\end{array}$ & $\begin{array}{l}74 \\
48\end{array}$ & $\begin{array}{l}26 \\
20\end{array}$ & $\begin{array}{l}\text { Coarse-med-fine } \\
\text { organic }\end{array}$ & $\begin{array}{l}\text { sandy clay loam } \\
\text { loam }\end{array}$ \\
\hline Tongyu-Cropland & $\begin{array}{l}184 \\
146\end{array}$ & $\begin{array}{l}\text { Cropland } \\
\text { Woody Grassland }\end{array}$ & $\begin{array}{l}60 \\
38\end{array}$ & $\begin{array}{l}35 \\
32\end{array}$ & $\begin{array}{l}\text { Coarse-med-fine } \\
\text { medium-fine }\end{array}$ & $\begin{array}{l}\text { sandy clay } \\
\text { clay loam }\end{array}$ \\
\hline Bondville & $\begin{array}{l}216 \\
213\end{array}$ & $\begin{array}{l}\text { Cropland } \\
\text { (Grassland) }\end{array}$ & $\begin{array}{r}8 \\
34\end{array}$ & $\begin{array}{l}27 \\
25\end{array}$ & $\begin{array}{l}\text { organic } \\
\text { organic }\end{array}$ & $\begin{array}{l}\text { silty loam/silt } \\
\text { loam }\end{array}$ \\
\hline Tumbarumba & $\begin{array}{r}1200 \\
914\end{array}$ & $\begin{array}{l}\text { Evergreen } \\
\text { Broadleaf forest } \\
\text { Cropland* }\end{array}$ & $\begin{array}{l}33.5 \\
59\end{array}$ & $\begin{array}{l}32.5 \\
23\end{array}$ & $\begin{array}{l}\text { Medium-fine } \\
\text { Coarse-med-fine }\end{array}$ & $\begin{array}{l}\text { clay loam } \\
\text { sandy clay loam }\end{array}$ \\
\hline
\end{tabular}

and temporally to the desired forcing resolutions. Downward shortwave and longwave radiation fluxes are estimated using a procedure and cloud and snow products from the U.S. Air Force Weather Agency's (AFWA) Agricultural Meteorology modeling system (AGRMET). The snow product is the AFWA daily, 48-km global snow depth analysis (Kopp and Kiess 1996). The cloud product is AFWA's hourly, 24-km World Wide Merged Cloud Analysis (WWMCA). These are used to calculate surface downward shortwave and longwave radiation based on the algorithms of Shapiro (1987) and Idso (1981). The cloud and snow products are derived primarily from observations made by Defense Meteorological Satellite Program and NOAA geostationary and polar orbiting satellites.

\section{Method}

Experiments were designed to test sensitivity by varying each option (land characteristic or forcing field, or model) one at a time, leaving everything else identical. For each of the four reference sites, and for each of the three LSMs, eight single-pixel simulations were performed, for a total of 96 . The sets of eight simulations consisted of one control run, two precipitation forcing experiments, two radiation forcing experiments, and one experiment each for land cover class, soil type, and elevation. The experimental timeframe was CEOP's Enhanced Observing Period 3 (EOP3): 1 October 2002 to 30 September 2003. Prior to that, the simulations were initialized with soil moisture at 30\% (45\% for CLM) on 0Z 1 January 1985 and allowed to spin-up for 17 years and nine months. The forcing during the spin-up period consisted of biascorrected reanalysis data produced by Berg et al. (2003) through 1999, followed by GDAS data. The LSM and land characteristics (land cover, soil, and elevation) were consistent between the spin-up and experimental periods, dictated by the configuration of the particular experiment. The model time step was 15 minutes and output was recorded hourly.

Sections 4.1 through 4.6 describe the control and experimental simulations. Precipitation and downward radiation (shortwave and longwave) varied between the station observations, GDAS analyses, and observation based products. Each of the three land characteristics was set to vary between what was observed at the station and the GLDAS standard input, or a likely alternative if those two agreed (Table 1). Individual model parameters were set by the GLDAS or model defaults or indexed to the land characteristics and seasons. In particular, Noah prescribes greenness fraction, quarterly snow free albedo, maximum albedo, and bottom soil temperature; CLM requires soil color, $L A I$, and stem area index (SAI) input fields; and Mosaic requires soil porosity, slope, $L A I$, and $S A I$ fields. The greenness, $L A I$, and $S A I$ fields vary monthly. The eight configurations were applied to all three land surface models: Noah, CLM, and Mosaic.

Three output variables were examined: evapotranspiration $\left[\mathrm{mm}\right.$ month $\left.^{-1}\right]$, sensible 
heat flux $\left[\mathrm{W} \mathrm{m}^{-2}\right]$, and top layer volumetric soil moisture [\%]. Time series of each were compared among the experiments at a given location in order to assess sensitivity. The potential for accurately simulating reality was evaluated using the field observations of the three variables. For soil moisture, only the top layer was examined because it is the most dynamic. The top layer in situ observation depths were $8 \mathrm{~cm}$ (Lindenberg), $5 \mathrm{~cm}$ (Tongyu), $10 \mathrm{~cm}$ (Bondville), and $15 \mathrm{~cm}$ (Tumbarumba). The top layer soil depths for Noah, CLM, and Mosaic were $10 \mathrm{~cm}, 1.8 \mathrm{~cm}$, and $2 \mathrm{~cm}$, respectively. Changing a model's soil layer depths from those set by the developers can have non-linear effects on the state and flux computations and typically requires tuning. For that reason the LSM soil depths were not adjusted to match the observation depths, and thus the evaluation is imperfect.

\subsection{Control runs}

A control run was performed for each of the three models, at each of the four locations (for a total of twelve), as a baseline for comparing the experimental simulations described next. Similarly, twelve instances of each experiment were run. The CEOP reference site observations were the basis for the forcing and land characteristics for the control run, and these inputs were varied one at a time in the experiments. Forcing gaps at Tongyu in October (19 days), late December to mid-February (64 days), and mid-April to mid-May (28 days) were filled by standard GLDAS forcing data, as were shorter gaps at all sites.

\subsection{Elevation}

The nearest GTOPO30 value was used to specify elevation in this experiment. Temperature, pressure, humidity, and longwave radiation were adjusted for the difference between the GTOPO30 and site elevations. The GTOPO30 value was low at all sites, by $3 \mathrm{~m}$ to $286 \mathrm{~m}$. The difference was less than $5 \mathrm{~m}$ at two sites.

\subsection{Soil type}

In this experiment, percentages of sand, silt, and clay were derived from the Reynolds soil dataset. Based on these, Noah (Zobler) and Mosaic (USDA) assign a soil type, which in turn is indexed to soil parameters including porosity
(Noah only), wilting point, and the $b$ parameter. Porosity values for Mosaic were taken directly from the Reynolds dataset. Similarly, soil color data (Dickinson et al. 1993) was used for all CLM simulations. Replacing the sand, silt, and clay percentages effected texture class changes in all cases except for Noah (Zobler) in Bondville.

\subsection{Land cover}

The $1 \mathrm{~km}$ UMD dataset was aggregated up to $0.25^{\circ}$ and $1.0^{\circ}$, and the predominant land cover types at those three resolutions were determined. The first to differ from the site description was used in this experiment. All sites are in or adjacent to cropland type vegetation, except for Tumbarumba, which lies in a forest.

\subsection{Precipitation forcing}

Two products, GDAS and disaggregated CMAP, were used to test sensitivity to precipitation forcing. The comprehensive evaluation of global precipitation datasets by Gottschalck et al. (2005) showed that these two are reasonably faithful in terms of timing and seasonal accumulations.

\subsection{Radiation forcing}

Similarly, the GDAS and AGRMET products were used to test sensitivity to downward radiation forcing. Shortwave and longwave radiation were varied together, i.e., each simulation used one source for both. Both products compare well with ground based observations (C.-J. Meng, NCEP, personal communication, 2006).

\section{Results}

\subsection{Seasonal sensitivity}

A total of 96 12-month simulations were completed. From their output, accumulated evapotranspiration, mean sensible heat flux, and mean top layer soil moisture content were computed on a monthly basis for October 2002 to September 2003. To summarize the results, the root-mean-square (RMS) of difference between each experimental simulation (with a single non-standard option) and its control (one for each model with standard options) was computed by season and by model, and then normalized by dividing by the seasonal mean of the control. Figure 1 presents these results averaged over the three LSMs and over each 


\begin{tabular}{|c|c|c|c|c|c|c|c|}
\hline ET & Site & Elevation & Soils & Land cover & Precipitation & Radiation & Models \\
\hline \multirow[t]{4}{*}{ DJF } & Tongyu & 0.01 & 0.18 & 0.03 & 0.72 & 0.03 & 0.46 \\
\hline & Lindenberg & 0.00 & 0.08 & 0.00 & 0.14 & 0.16 & 0.35 \\
\hline & Bondville & 0.05 & 0.25 & 0.05 & 0.76 & 0.16 & 1.13 \\
\hline & Tumbarumba & 0.03 & 0.02 & 0.12 & 0.11 & 0.04 & 0.17 \\
\hline \multirow[t]{4}{*}{ MAM } & Tongyu & 0.00 & 0.23 & 0.09 & 0.37 & 0.03 & 0.49 \\
\hline & Lindenberg & 0.00 & 0.06 & 0.08 & 0.07 & 0.13 & 0.76 \\
\hline & Bondville & 0.01 & 0.08 & 0.06 & 0.33 & 0.11 & 0.68 \\
\hline & Tumbarumba & 0.04 & 0.03 & 0.13 & 0.14 & 0.09 & 0.14 \\
\hline \multirow[t]{4}{*}{\begin{tabular}{|l|} 
JJA \\
\end{tabular}} & Tongyu & 0.00 & 0.09 & 0.08 & 0.19 & 0.03 & 0.14 \\
\hline & Lindenberg & 0.00 & 0.05 & 0.04 & 0.13 & 0.12 & 1.08 \\
\hline & Bondville & 0.00 & 0.03 & 0.07 & 0.32 & 0.04 & 0.48 \\
\hline & Tumbarumba & 0.26 & 0.02 & 0.75 & 0.41 & 0.36 & 0.94 \\
\hline \multirow[t]{4}{*}{ SON } & Tongyu & 0.00 & 0.08 & 0.07 & 0.21 & 0.03 & 0.34 \\
\hline & Lindenberg & 0.01 & 0.04 & 0.05 & 0.08 & 0.05 & 0.51 \\
\hline & Bondville & 0.04 & 0.12 & 0.15 & 0.27 & 0.06 & 0.73 \\
\hline & Tumbarumba & 0.09 & 0.02 & 0.25 & 0.11 & 0.10 & 0.33 \\
\hline $\mathbf{Q h}$ & Site & Elevation & Soils & Land cover & Precipitation & Radiation & Models \\
\hline \multirow[t]{4}{*}{ DJF } & Tongyu & 0.02 & 0.05 & 0.27 & 0.24 & 0.71 & 0.70 \\
\hline & Lindenberg & -0.07 & -0.41 & -0.02 & -1.06 & -3.62 & -1.36 \\
\hline & Bondville & 0.04 & 0.10 & 0.04 & 0.80 & 0.40 & 0.76 \\
\hline & Tumbarumba & 0.03 & 0.02 & 0.31 & 0.11 & 0.73 & 0.44 \\
\hline \multirow[t]{4}{*}{ MAM } & Tongyu & 0.00 & 0.09 & 0.24 & 0.12 & 0.21 & 0.64 \\
\hline & Lindenberg & 0.03 & 0.20 & 0.26 & 0.21 & 0.90 & 1.69 \\
\hline & Bondville & 0.01 & 0.06 & 0.06 & 0.27 & 0.25 & 0.28 \\
\hline & Tumbarumba & 0.03 & 0.02 & 0.19 & 0.10 & 0.94 & 0.89 \\
\hline \multirow[t]{4}{*}{ JJA } & Tongyu & 0.00 & 0.18 & 0.36 & 0.41 & 0.65 & 0.46 \\
\hline & Lindenberg & 0.01 & 0.06 & 0.06 & 0.16 & 0.40 & 1.26 \\
\hline & Bondville & 0.00 & 0.10 & 0.26 & 1.11 & 0.28 & 1.55 \\
\hline & Tumbarumba & 1.18 & 0.09 & 2.45 & 2.53 & 4.80 & 4.79 \\
\hline \multirow[t]{4}{*}{ SON } & Tongyu & 0.01 & 0.09 & 0.31 & 0.32 & 0.37 & 0.63 \\
\hline & Lindenberg & 0.21 & 0.27 & 0.30 & 0.49 & 0.93 & 2.44 \\
\hline & Bondville & 0.06 & 0.10 & 0.13 & 0.18 & 0.07 & 0.36 \\
\hline & Tumbarumba & 0.10 & 0.02 & 0.25 & 0.20 & 0.68 & 0.41 \\
\hline SM & Site & Elevation & Soils & Land cover & Precipitation & Radiation & Models \\
\hline \multirow[t]{4}{*}{ DJF } & Tongyu & 0.00 & 0.75 & 0.29 & 0.56 & 0.03 & 0.33 \\
\hline & Lindenberg & 0.02 & 0.10 & 0.01 & 0.13 & 0.05 & 0.25 \\
\hline & Bondville & 0.10 & 0.14 & 0.10 & 0.13 & 0.07 & 0.24 \\
\hline & Tumbarumba & 0.02 & 0.16 & 0.10 & 0.09 & 0.05 & 0.36 \\
\hline \multirow[t]{4}{*}{ MAM } & Tongyu & 0.00 & 0.31 & 0.09 & 0.11 & 0.01 & 0.20 \\
\hline & Lindenberg & 0.03 & 0.15 & 0.06 & 0.10 & 0.03 & 0.25 \\
\hline & Bondville & 0.00 & 0.04 & 0.02 & 0.12 & 0.02 & 0.08 \\
\hline & Tumbarumba & 0.02 & 0.17 & 0.06 & 0.11 & 0.06 & 0.42 \\
\hline \multirow[t]{4}{*}{ JJA } & Tongyu & 0.00 & 0.13 & 0.04 & 0.05 & 0.03 & 0.05 \\
\hline & Lindenberg & 0.02 & 0.26 & 0.11 & 0.24 & 0.12 & 0.77 \\
\hline & Bondville & 0.00 & 0.04 & 0.03 & 0.23 & 0.01 & 0.11 \\
\hline & Tumbarumba & 0.04 & 0.12 & 0.04 & 0.22 & 0.01 & 0.21 \\
\hline \multirow[t]{4}{*}{ SON } & Tongyu & 0.00 & 0.26 & 0.11 & 0.27 & 0.02 & 0.20 \\
\hline & Lindenberg & 0.01 & 0.12 & 0.03 & 0.04 & 0.02 & 0.16 \\
\hline & Bondville & 0.00 & 0.04 & 0.01 & 0.09 & 0.01 & 0.08 \\
\hline & Tumbarumba & 0.04 & 0.14 & 0.13 & 0.21 & 0.02 & 0.25 \\
\hline & & low & low-mid & mid-low & mid & mid-high & high \\
\hline
\end{tabular}

Fig. 1. Sensitivity by season, represented by the normalized $R M S$ of the difference between output from the experimental simulation and the control, for evapotranspiration, sensible heat flux, and top layer soil moisture. Differences were normalized by dividing by the seasonal mean of the control, thus the numbers are unitless. The type of sensitivity is indicated by the column heading. Results were averaged over the three LSMs and over the three months of the season. Results for the precipitation and radiation experiments were also averaged over the two alternative forcings tested for each. Table cells are colorized to guide the reader's eyes, with the highest sensitivity for a given row (site and season) shown in red, followed by orange, yellow, green, blue, and white in order of decreasing sensitivity. 
Table 2. Seasonal mean precipitation $\left[\mathrm{mm} \mathrm{month}{ }^{-1}\right]$, evapotranspiration $\left[\mathrm{mm} \mathrm{month} \mathrm{m}^{-1}\right]$, sensible heat flux [ $\left.\mathrm{W} \mathrm{m}^{-2}\right]$, and top layer volumetric soil moisture content [\%] from reference site observations during EOP3. Soil moisture observations were taken at depths of $5 \mathrm{~cm}$ (Tongyu), $8 \mathrm{~cm}$ (Lindenberg), $10 \mathrm{~cm}$ (Bondville), and $15 \mathrm{~cm}$ (Tumbarumba).

\begin{tabular}{|c|c|c|c|c|c|}
\hline Season & site & Precip & $E T$ & $Q h$ & $S M$ \\
\hline \multirow[t]{4}{*}{ DJF } & Tongyu & 0.00 & 2.06 & 12.31 & 3.78 \\
\hline & Lindenberg & 19.74 & 7.21 & -2.44 & 27.35 \\
\hline & Bondville & 34.93 & 4.24 & 10.50 & 33.91 \\
\hline & Tumbarumba & 43.38 & 103.16 & 86.38 & 27.19 \\
\hline \multirow[t]{4}{*}{ MAM } & Tongyu & 6.27 & 15.01 & 40.47 & 10.10 \\
\hline & Lindenberg & 22.78 & 39.54 & 11.75 & 17.32 \\
\hline & Bondville & 48.80 & 38.47 & 38.38 & 40.00 \\
\hline & Tumbarumba & 44.58 & 39.12 & 49.57 & 28.55 \\
\hline \multirow[t]{4}{*}{ JJA } & Tongyu & 78.37 & 78.26 & 29.04 & 26.97 \\
\hline & Lindenberg & 42.32 & 52.36 & 31.95 & 6.57 \\
\hline & Bondville & 80.53 & 109.74 & 25.02 & 40.46 \\
\hline & Tumbarumba & 207.08 & 17.85 & 5.25 & 42.16 \\
\hline \multirow[t]{4}{*}{$\overline{\mathrm{SON}}$} & Tongyu & 8.53 & 19.37 & 17.85 & 13.09 \\
\hline & Lindenberg & 58.80 & 27.63 & 4.37 & 19.22 \\
\hline & Bondville & 70.00 & 27.58 & 32.69 & 39.15 \\
\hline & Tumbarumba & 76.67 & 69.63 & 71.12 & 35.27 \\
\hline
\end{tabular}

season: December-January-February (DJF), March-April-May (MAM), June-July-August (JJA), and September-October-November (SON). For reference, Table 2 provides the seasonal means of the observed values of the same three variables and precipitation for each site. The sites are ordered in Fig. 1 according to the accumulated precipitation amount during EOP3, which was lowest at Tongyu $(280 \mathrm{~mm})$, followed by Lindenberg (431 mm), Bondville (702 mm), and Tumbarumba (1115 mm). During EOP3, precipitation was heaviest in JJA (SON at Lindenberg) and lightest in DJF.

Evapotranspiration $(E T)$ was most or nextto-most sensitive to LSM physics in all cases, with normalized seasonal $R M S$ values as large as 1.13 (Fig. 1) and non-normalized values as large as $57 \mathrm{~mm} \mathrm{month}{ }^{-1}$. Precipitation forcing had the second greatest influence, followed by land cover and radiation. Soil type generally had a small influence. $E T$ was insensitive to elevation changes except in Tumbarumba, where the difference between the control and experimental elevations was nearly $300 \mathrm{~m}$. In general, sensitivities were larger during the wetter seasons, which also happen to have more radiation input, reflecting a larger possible range of ET rates. Sensitivity to precipitation was always strong at Lindenberg and Bondville. Also, at Lindenberg, sensitivity to radiation was just as or larger than to precipitation. At Tongyu, sensitivity to precipitation was large relative to other options in the dry winter, when a small change in precipitation has a relatively large influence on the water budget. Similarly, the largest sensitivity to precipitation occurred in the driest season at Tumbarumba. The degree to which a location is water- or energy-limited is reflected in its sensitivity to precipitation and radiation. Sensitivity to vegetation is the second largest at Tumbarumba, where the experiment changed the land cover type from evergreen broadleaf forest to cropland. That change was dramatic 
relative to the difference between grassland and cropland.

In general, sensible heat flux $(Q h)$ was most sensitive to the choice of LSM (Fig. 1). As would be expected, $Q h$ also was very sensitive to incoming radiation, particularly in the winter and summer. The largest normalized seasonal $R M S$ value, 4.80 , and the largest nonnormalized value, $63 \mathrm{~W} \mathrm{~m}^{-2}$, both were caused by differences in radiation forcing. At Tumbarumba, $Q h$ was most sensitive to radiation in all seasons. This is explained in part by the abundant precipitation Tumbarumba receives in all seasons, so that surface processes are energy limited. $Q h$ was most sensitive to radiation in three of eight cases at Lindenberg and Bondville, and it was most sensitive to the LSM in the other five. Significant sensitivities to precipitation and land cover were also exhibited. Seasonal $Q h$ sensitivity to precipitation mirrored that of evapotranspiration, increasing towards JJA at each site. $Q h$ was consistently more sensitive to precipitation than to radiation at Bondville. On first inspection, this appears to reflect the influence on the energy balance that precipitation exerts through its control of ET, assuming Bondville was indeed water limited during EOP3. However, there were also large differences between the control and experimental precipitation forcing data at that site, relative to the differences in radiation forcing data, which would tend to cause greater apparent precipitation sensitivity. Sensitivity of $Q h$ to soil and elevation was generally small.

Top layer volumetric soil moisture $(S M)$ was most sensitive to model physics, but soil and precipitation were almost as important (Fig. 1). The largest normalized seasonal $R M S$ values were 0.77 for choice of LSM, 0.56 for precipitation forcing, and 0.75 for soils. The largest non-normalized values were $12 \%, 9 \%$, and $5 \%$ volumetric soil water content, respectively. At Tongyu, which was typically the driest of the four sites, the choice of soil properties was the most important factor. $S M$ peaked in DJF and reached a minimum in JJA, except at Tongyu, where the soil was wettest in JJA. The variability of $S M$ output from the experiments for a particular LSM and location was well correlated with precipitation. The sensitivity of $S M$ to precipitation peaked during JJA and SON. The sensitivity of $E T$ and $Q h$ to land cover was greater during warmer seasons. For $S M$, sensitivity to land cover increased with wetness at Tongyu (driest) and Tumbarumba (wettest) and decreased with wetness at Lindenberg and Bondville. Sensitivity to radiation was generally weak, increasing slightly with wetness at Tongyu, Lindenberg, and Bondville. Sensitivity to elevation was small.

\subsection{Model specific sensitivity}

The seasonal analysis demonstrated that the largest variation in evapotranspiration, sensible heat flux, and soil moisture was caused by differences in model physics. To summarize model specific sensitivity to land characteristics and forcing, calculated $R M S$ values were averaged over all of EOP3 separately by LSM. The results are presented in Fig. 2. As shown in the previous section, after model physics, ET was typically most sensitive to precipitation forcing, $Q h$ was most sensitive to radiation, and $S M$ was very sensitive to both precipitation and soils. Two major exceptions were that ET was most sensitive to land cover at Tumbarumba (where forest became cropland), and that sensible heat flux was most sensitive to precipitation at Bondville.

Noah typified the responses of the LSMs to the experiments, in that $E T$ was most sensitive to precipitation, $Q h$ was most sensitive to radiation, and $S M$ was highly sensitive to both precipitation and soils. Changing between cropland and grassland (Lindenberg and Bondville) had no effect on Noah because the two are treated equally in the model. Noah's sensitivity to soil at Bondville was nil because the difference in the percentages of sand, silt, and clay was not enough to change the Zobler soil type.

CLM was the most sensitive of the LSMs to land cover at the two sites where changes were made between cropland and grassland, illustrating a significant difference in the treatment of these vegetation classes in the model. Its $E T$ was unusually sensitive to land cover. CLM was the least sensitive of the LSMs to soil properties, except at Bondville, where it was actually the most sensitive. CLM was generally the most sensitive of the LSMs to elevation changes, with the notable exception of $Q h$ at Tumbarumba. As with the other LSMs, its $Q h$ was most sensitive to radiation, and the nor- 


\begin{tabular}{|c|c|c|c|c|c|c|}
\hline ET & Model & Elevation & Soils & Land cover & Precipitation & Radiation \\
\hline \multirow[t]{3}{*}{ Tongyu } & NOAH & 0.00 & 0.08 & 0.17 & 0.28 & 0.06 \\
\hline & CLM & 0.00 & 0.02 & 0.05 & 0.36 & 0.04 \\
\hline & MOSAIC & 0.00 & 0.37 & 0.09 & 0.37 & 0.04 \\
\hline \multirow[t]{3}{*}{ Lindenberg } & NOAH & 0.00 & 0.04 & 0 & 0.11 & 0.09 \\
\hline & CLM & 0.01 & 0.01 & 0.23 & 0.18 & 0.06 \\
\hline & MOSAIC & 0.00 & 0.07 & 0.00 & 0.03 & 0.12 \\
\hline \multirow[t]{3}{*}{ Bondville } & $\mathrm{NOAH}$ & 0.00 & 0 & $\overline{0}$ & 0.26 & 0.05 \\
\hline & CLM & 0.03 & 0.11 & 0.30 & 0.56 & 0.04 \\
\hline & MOSAIC & 0.00 & 0.05 & 0.00 & 0.13 & 0.05 \\
\hline \multirow[t]{3}{*}{ Tumbarumba } & NOAH & 0.07 & 0.01 & 0.28 & 0.27 & 0.08 \\
\hline & CLM & 0.17 & 0.07 & 0.48 & 0.24 & 0.29 \\
\hline & MOSAIC & 0.14 & 0.04 & 0.42 & 0.22 & 0.16 \\
\hline Qh & Model & Elevation & Soils & Land cover & Precipitation & Radiation \\
\hline \multirow[t]{3}{*}{ Tongyu } & NOAH & 0.00 & 0.04 & 0.11 & 0.15 & 0.28 \\
\hline & CLM & 0.01 & 0.02 & 0.13 & 0.18 & 0.33 \\
\hline & MOSAIC & 0.00 & 0.14 & 0.30 & 0.17 & 0.24 \\
\hline \multirow[t]{3}{*}{ Lindenberg } & NOAH & 0.01 & 0.07 & 0 & 0.18 & 0.52 \\
\hline & CLM & 0.03 & 0.01 & 0.16 & 0.13 & 0.35 \\
\hline & MOSAIC & 0.01 & 0.35 & 0.00 & 0.18 & 0.65 \\
\hline \multirow[t]{3}{*}{ Bondville } & $\mathrm{NOAH}$ & 0.00 & 0 & 0 & 0.55 & 0.28 \\
\hline & CLM & 0.05 & 0.11 & 0.30 & 0.48 & 0.16 \\
\hline & MOSAIC & 0.00 & 0.16 & 0.00 & 0.50 & 0.25 \\
\hline \multirow[t]{3}{*}{ Tumbarumba } & $\mathrm{NOAH}$ & 0.20 & 0.02 & 0.42 & 0.47 & 0.97 \\
\hline & CLM & 0.15 & 0.14 & 1.20 & 0.57 & 6.42 \\
\hline & MOSAIC & 0.08 & 0.02 & 0.42 & 0.19 & 0.66 \\
\hline SM & Model & Elevation & Soils & Land cover & Precipitation & Radiation \\
\hline \multirow[t]{3}{*}{ Tongyu } & $\mathrm{NOAH}$ & 0.00 & 0.37 & 0.10 & 0.24 & 0.03 \\
\hline & CLM & 0.00 & 0.08 & 0.03 & 0.16 & 0.03 \\
\hline & MOSAIC & 0.00 & 0.30 & 0.12 & 0.09 & 0.02 \\
\hline \multirow[t]{3}{*}{ Lindenberg } & NOAH & 0.00 & 0.04 & 0 & 0.04 & 0.02 \\
\hline & CLM & 0.04 & 0.05 & 0.10 & 0.20 & 0.06 \\
\hline & MOSAIC & 0.01 & 0.19 & 0.00 & 0.03 & 0.02 \\
\hline \multirow[t]{3}{*}{ Bondville } & NOAH & 0.00 & 0 & 0 & 0.19 & 0.02 \\
\hline & CLM & 0.10 & 0.21 & 0.17 & 0.25 & 0.07 \\
\hline & MOSAIC & 0.00 & 0.08 & 0.00 & 0.23 & 0.03 \\
\hline \multirow[t]{3}{*}{ Tumbarumba } & $\mathrm{NOAH}$ & 0.04 & 0.19 & 0.11 & 0.14 & 0.03 \\
\hline & CLM & 0.04 & 0.19 & 0.11 & 0.32 & 0.08 \\
\hline & MOSAIC & 0.05 & 0.28 & 0.15 & 0.32 & 0.04 \\
\hline
\end{tabular}

\begin{tabular}{l|l|l|l|l} 
low & mid-low & mid & mid-high & high
\end{tabular}

Fig. 2. Sensitivity by model, represented by the normalized $R M S$ of the difference between output from the experimental simulation and the control, for evapotranspiration, sensible heat flux, and top layer soil moisture. Differences were normalized by dividing by the seasonal mean of the control, thus the numbers are unitless. The type of sensitivity is indicated by the column heading. Results were averaged over the entire period, 1 October 2002 to 30 September 2003. Results for the precipitation and radiation experiments were also averaged over the two alternative forcings tested for each. Table cells are colorized to guide the reader's eyes, with the highest sensitivity for a given row (site and season) shown in red, followed by orange, yellow, green, and blue in order of decreasing sensitivity. 

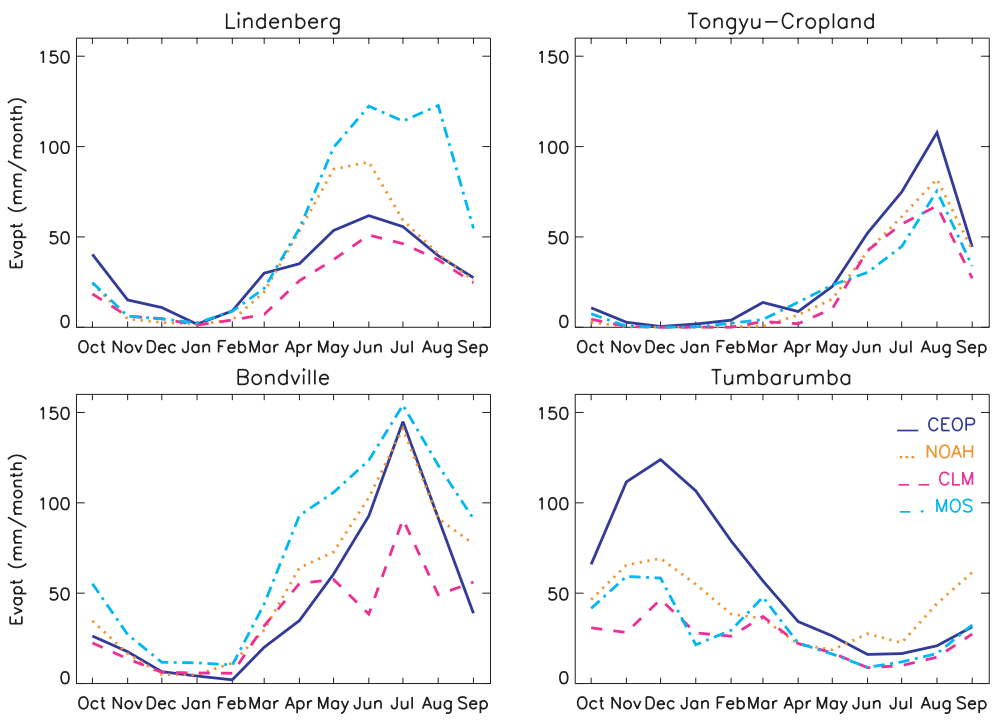

Fig. 3. Monthly accumulated evapotranspiration [mm month ${ }^{-1}$ from October 2002 to September 2003. Lines represent the CEOP reference site observations (blue) and control run output from the three LSMs: Noah (orange), CLM (pink), and Mosaic (turquoise).

malized $R M S$ at Tumbarumba, 6.42 , was by far the largest value. CLM's soil moisture had the strongest sensitivity to precipitation of the three LSMs.

Mosaic was the most sensitive of the LSMs to soil properties. All three output variables were strongly influenced by land cover, relative to the other LSMs, at Tongyu and Tumbarumba. Interestingly, Mosaic's ET was most sensitive to radiation at Lindenberg, not precipitation or land cover. Another unusual case was Mosaic's $Q h$ being most sensitive to land cover, rather than a forcing variable, at Tongyu.

\subsection{Evaluation of output}

High quality, co-located observations were the basis for the forcing and land attribute inputs of the control runs. Assuming these data were essentially free from inconsistencies and biases, they should have provided the LSMs a fair opportunity to simulate reality. The accuracies of the modeled evapotranspiration, sensible heat flux, and soil moisture are summarized below. However, rather than delving into the model physics to explain errors, the primary goal here is to evaluate the potential of each LSM, as currently parameterized, to produce accurate results given a likely range of input forcing and land characteristic data.
Comparisons between observed and simulated monthly accumulated evapotranspiration are shown in Fig. 3. Figure 4 plots the differences between the various experimental runs and the control. Modeled ET generally captured the observed seasonal cycle. On average, the model estimates had a low bias at Tongyu (the driest site) and Tumbarumba (the wettest site), and a high or no bias at Lindenberg and Bondville. Noah's $E T$ was higher than that of CLM and Mosaic at the former two sites, whereas $E T$ from Mosaic was higher than that of CLM and Noah at the latter two sites. CLM displayed a consistently low bias with respect to the observations and other LSMs. Mosaic's SM at Tumbarumba is much lower than the observations and other models, which suggests that Mosaic allows ET to continue as moisture levels become small. Most instances of ET overestimation (underestimation) can be explained by sensible heat flux being low (high) at the Tongyu, Lindenberg, and Bondville site (not shown). Only at Tumbarumba are $E T, Q h$, and $S M$ all smaller than the observations. Precipitation amounts from GDAS and CMAP are about $14 \mathrm{~mm}$ month ${ }^{-1}$ higher than the observations during JJA at Tongyu. This explains, in part, a $\sim 9 \mathrm{~mm}$ month $^{-1}$ high bias in modeled ET. 

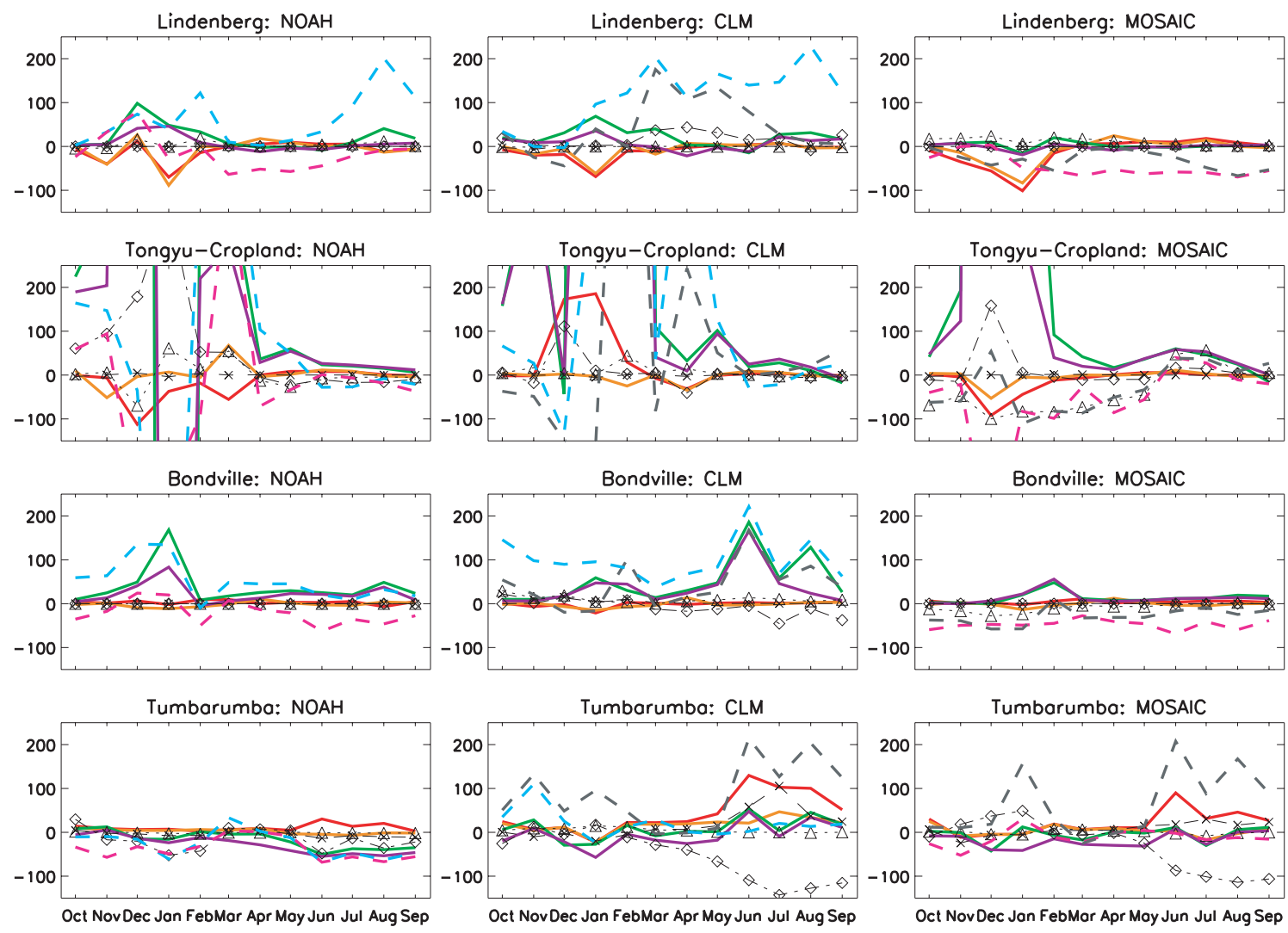

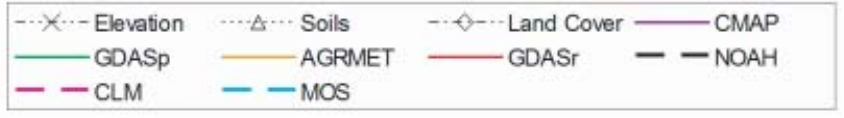

Fig. 4. Deviation of monthly accumulated evapotranspiration [mm month $\left.{ }^{-1}\right]$ from the control run of each LSM, October 2002 to September 2003. Rows, top to bottom: Tongyu, Lindenberg, Bondville, and Tumbarumba CEOP reference sites. Columns, left to right: Noah, CLM, and Mosaic LSMs. Lines show the deviation of the elevation (GTOPO30), soil (Reynolds), land cover (Domveg), CMAP precipitation, GDAS precipitation (GDASp), AGRMET radiation, and GDAS radiation (GDASr) experiment output from the control for the given model. Also plotted are the other two LSMs' control output differences (NOAH, CLM, and MOS) from the particular LSM.

Figure 5 illustrates the potential for the LSMs to correctly simulate observed $E T, Q h$, and $S M$, for each location, for each month of EOP3. Plotted are the observed monthly values and those simulated by the Noah, CLM, and Mosaic control (observation forced) runs. Error bars depict the range of possible outcomes given the sensitivity to the alternative land characteristic and forcing fields used in the experiments. These were computed as

Range $= \pm \sqrt{R M S_{L C}^{2}+R M S_{S}^{2}+R M S_{E}^{2}+R M S_{P}^{2}+R M S_{R}^{2}}$ where $R M S$ is the root mean square difference between the experimental and control outputs for the five sensitivities tested: land cover $(L C)$, soil $(S)$, elevation $(E)$, precipitation $(P)$, and radiation $(R)$.

The three LSMs are capable of simulating the observed monthly ET (i.e., the observed values are within the error bars) roughly half of the time. Noah had fair to good potential at Tongyu and Bondville, CLM's potential was good at Lindenberg and Bondville, and Mosaic's potential was good at Tongyu and Tumbarumba. CLM's $E T$ was typically lower than that 

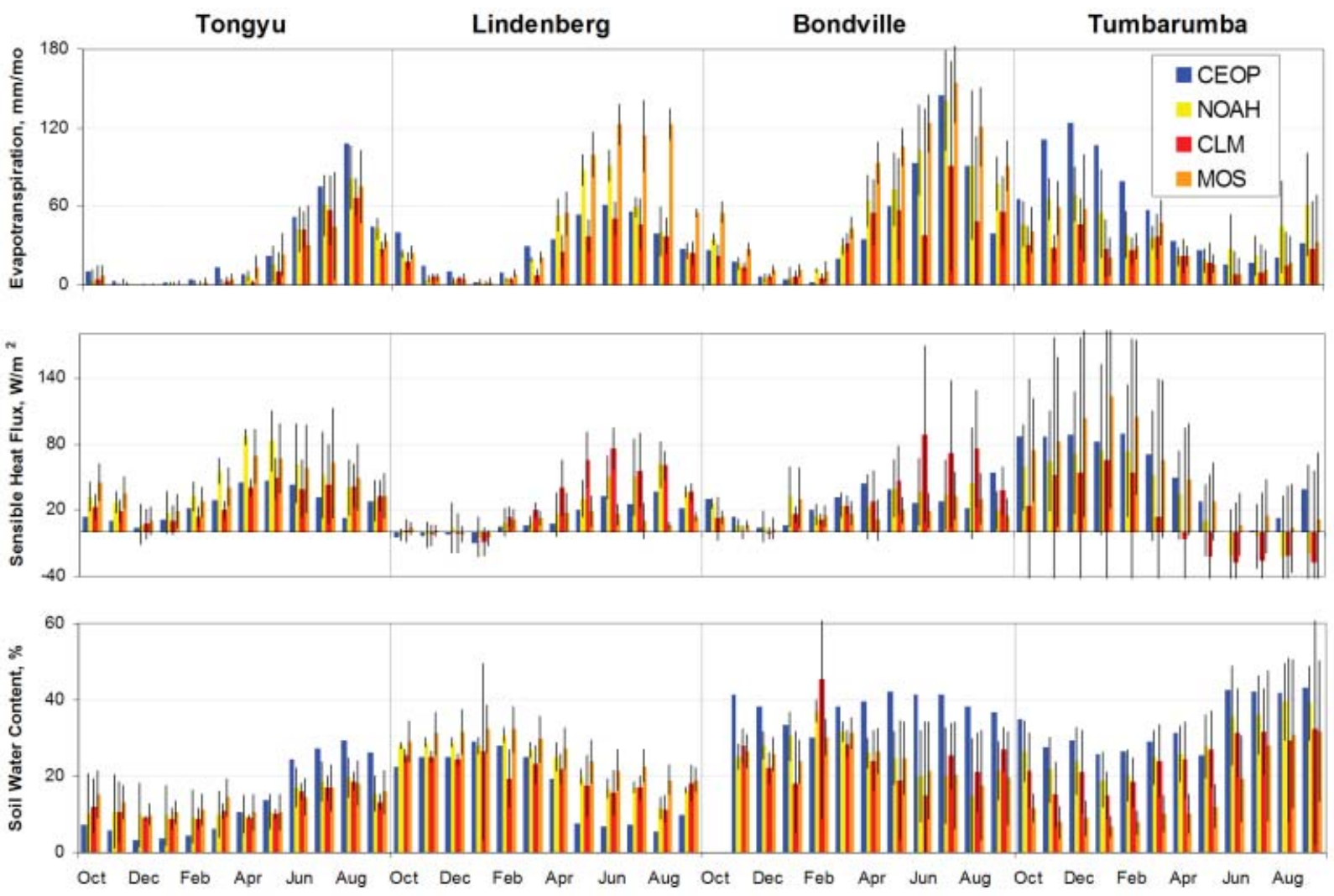

Fig. 5. Monthly evapotranspiration [mm month ${ }^{-1}$, top, sensible heat flux [W $\mathrm{m}^{-2}$ ], middle, and mean volumetric water content in the top soil layer [\%], bottom, for each site. Plotted are the CEOP data and output from the Noah, CLM, and Mosaic control runs. Error bars represent the expected range of outcomes based on the uncertainty in the land properties and forcing.

of the other two models, but relative to the observations none of the models had a consistent bias across all sites.

The LSMs were shown to be capable of simulating $Q h$ in most cases. However, this was not because the model estimates were particularly good, but because the ranges of possible outcomes were larger, relative to the observed and simulated values, than was the case for $E T$ or $S M$. In other words, $Q h$ is highly sensitive to land and forcing data, so that there is the potential for either very good or very bad results. This is especially true at Tumbarumba, where the range was often more than twice as large as the observed values.

The potential for the models to simulate observed $S M$ was often poor. At Tongyu and Lindenberg, this was mainly due to the fact that the dynamic ranges of soil moisture in the models were too narrow. The fact that the top soil layers in CLM and Mosaic were shallow $(1.8 \mathrm{~cm}$ and $2.0 \mathrm{~cm})$ relative to the observation depths, which ranged from 5 to $15 \mathrm{~cm}$, is not a useful explanation for their narrow moisture ranges because Noah, with a $10 \mathrm{~cm}$ soil layer, had the same problem. Thus it is likely an issue of calibration. Model developers frequently emphasize the optimization of simulated $E T$ or runoff at the expense of $S M$, any calibration was probably done using data from different locations. Furthermore, the dynamic range of soil moisture at a point tends to be larger than that averaged over the surrounding area $(\mathrm{Fa}-$ miglietti et al. 1999), and these LSMs were designed to model pixels, not points. All of the LSMs tended to underestimate $S M$ at Bondville, often below the range of possible outcomes. Results were better at Tumbarumba, 
except that Mosaic's $S M$ again was too low. Nevertheless, model biases were not consistent across sites.

\section{Summary and discussion}

The sensitivity of simulated evapotranspiration, sensible heat flux, and top layer soil moisture content to elevation, soils, land cover, precipitation and radiation forcing, and the physics of three LSMs was investigated. Each option was adjusted separately in simulations over four CEOP reference sites, where EOP3 surface flux and state observations and site characteristics were available. Rather than assessing sensitivity to a theoretical but unlikely range of inputs, this study focused on model responses to real differences in land properties and forcing from available global datasets, which is more relevant to the decisions that modelers face. The primary objectives of the study were to discover the relative importance of the input options and to determine whether observed values of $E T, Q h$, and $S M$ were within the range of outputs that could reasonably be expected from three state-of-the-art LSMs.

In agreement with previous studies, it was shown that three LSMs of similar complexity can produce significantly dissimilar surface output fields despite identical land characteristics and forcings. Thus choice of LSM is the most important influence on the simulation of surface water and energy partitioning. This highlights the importance of calibrating LSMs and improving their physics in order to increase accuracy, as opposed to just focusing on the inputs. Divergence between the models ranged from $13 \%$ to $113 \%$ of seasonal ET. Divergence of modeled $S M$ was somewhat smaller, $25 \%$ of mean on average. Differences in $S M$ were generally smaller in the wet seasons than the dry seasons. Conversely, differences in modeled $Q h$ were smaller in the dry seasons than the wet seasons, except at Tongyu, where the divergence of all three variables was consistently smaller in the wet season.

Beyond model physics, and in general at the sites studied, evapotranspiration was shown to be most sensitive to precipitation, followed by land cover and radiation. Sensible heat flux was most sensitive to radiation followed by precipitation and land cover. Soil moisture was most sensitive to precipitation, followed by soil and land cover. These results have implications for the refinement of the datasets used to parameterize and force land surface models. For example, if one's goal is improving the simulation of $S M$, having a good soil dataset is more important than if the goal is simulating ET. The importance of being in a water- versus energy-limited regime manifested itself in a shift in the sensitivity of all variables between precipitation and radiation forcing. Larger uncertainty in the forcing variables also increased apparent sensitivity, as exemplified by the higher $R M S$ values for $E T$ in the wet season when absolute errors in the precipitation products are larger. Similarly, the relatively large sensitivity to precipitation at Bondville is caused in part by large differences between the forcing options.

Based on the computed ranges of possible outcomes, the potential for the LSMs to accurately simulate $E T$ was fair. The potential for correctly simulating $S M$ appeared to be poor, but this may actually reflect differences between the observed and modeled soil depths. The potential for accurately simulating $Q h$ was good with respect to the range of possible outcomes, but unlikely given that the sensitivities were so high as to demand significant refinement of the input fields. These results, along with the demonstrated preeminence of model physics' control over output, emphasize that continued honing and calibration of the LSMs themselves will be essential to the accurate numerical simulation of land surface water and energy processes.

\section{Acknowledgments}

This work was supported by NASA's Energy and Water Cycle Study (NEWS). The authors wish to thank NOAA and AFWA for supplying meteorological forcing fields. Kevin Ellett of the University of Melbourne and United States Geological Survey and three anonymous reviewers provided valuable comments which improved the quality of this paper.

\section{References}

ALMA, 2002: Assistance for land modeling activities, Version 3, 〈http://www.lmd.jussieu.fr/ALMA/ >.

Bastidas, L.A., H.V. Gupta, S. Sorooshian, W.J. Shuttleworth, and Z.L. Yang, 1999: Sensitivity analysis of a land surface scheme using multi- 
criteria methods, J. Geophys. Res., 104(D16), 19481-19490.

Berg, A.A., J.S. Famiglietti, J.P. Walker, and P.R. Houser, 2003: Impact of bias correction to reanalysis products on simulations of North American soil moisture and hydrological fluxes, J. Geophys. Res., 108(D16), 4490, doi:10.1029/ 2002JD003334.

Betts, A., F. Chen, K. Mitchell, and Z. Janjic, 1997: Assessment of the land surface and boundary layer models in two operational versions of the NCEP Eta model using FIFE data. Mon. Wea. Rev., 125, 2896-2916.

Bonan, G.B., 1998: The land surface climatology of the NCAR Land Surface Model coupled to the NCAR Community Climate Model. J. Climate, 11, 1307-1326.

Chen, F., K. Mitchell, J. Schaake, Y. Xue, H. Pan, V. Koren, Y. Duan, M. Ek, and A. Betts, 1996: Modeling of land-surface evaporation by four schemes and comparison with FIFE observations. J. Geophys. Res., 101(D3), 7251-7268.

Chen, T.H. and 31 co-authors, 1997: Cabauw experimental results from the Project for Intercomparison of Land-surface Parameterization Schemes (PILPS), J. Climate, 10, 1194-1215.

Cosgrove, B.A. and 14 co-authors, 2003: Realtime and retrospective forcing in the North American Land Data Assimilation System (NLDAS) project, J. Geophys. Res., 108, 8842.

Crow, W.T., E.F. Wood, and M. Pan, 2003: Multiobjective calibration of land surface model evapotranspiration predictions using streamflow observations and spaceborne surface radiaometric temperature retrievals. J. Geophys. Res., 108(D23), 4725.

Dai, Y. and Q. Zeng, 1997: A land surface model (IAP94) for climate studies, Part I: Formulation and validation in off-line experiments. Advances in Atmos. Sci., 14, 443-460.

Dickinson, R.E., A. Henderson-Sellers, and P.J. Kennedy, 1993: Biosphere-Atmosphere Transfer Scheme (BATS) version $1 \mathrm{e}$ as coupled to the NCAR Community Climate Model. NCAR Tech. Note NCAR/TN-387+STR, 72 pp.

Dirmeyer, P.A., A.J. Dolman, and N. Sato, 1999: The Global Soil Wetness Project: A pilot project for global land surface modeling and validation. Bull. Amer. Meteor. Soc., 80, 851-878.

Ek, M.B., K.E. Mitchell, Y. Lin, E. Rogers, P. Grunmann, V. Koren, G. Gayno, and J.D. Tarpley, 2003: Implementation of Noah land surface model advances in the National Centers for Environmental Prediction operational mesoscale Eta model, J. Geophys. Res., 108(D22), 8851, doi:10.1029/2002JD003296.

Famiglietti, J.S., J.A. Devereaux, C.A. Laymon, T.
Tsegaye, P.R. Houser, T.J. Jackson, S.T. Graham, M. Rodell, and P.J. van Oevelen, 1999: Ground-based investigation of soil moisture variability within remote sensing footprints during the Southern Great Plains 1997 (SGP97) Hydrology Experiment, Wat. Resour. Res., 35, 1839-1851.

Gesch, D.B., K.L. Verdin, and S.K. Greenlee, 1999: New land surface digital elevation model covers the Earth. EOS, Transactions of the American Geophysical Union, v. 80, n. 6, pp 69-70.

Gottschalck, J., J. Meng, M. Rodell, and P. Houser, 2005: Analysis of multiple precipitation products and preliminary assessment of their impact on Global Land Data Assimilation System (GLDAS) land surface states, J. Hydromet., 6(5), 573-598.

Gupta, H.V., L.A. Bastidas, S. Sorooshian, W.J. Shuttleworth, and Z.L. Yang, 1999: Parameter estimation of a land surface scheme using multicriteria methods, J. Geophys. Res., 104(D16), 19491-19504.

Hansen, M.C., R.S. DeFries, J.R.G. Townshend, and R. Sohlberg, 2000: Global land cover classification at $1 \mathrm{~km}$ spatial resolution using a classification tree approach. International Journal of Remote Sensing, 21, 1331-1364.

Hill, C., C. Deluca, V. Balaji, M. Suarez, and A. da Silva, 2004: The architecture of the Earth system modeling framework, Computing in Science and Engineering, 6(1).

Hogue, T.S., L. Bastidas, H. Gupta, S. Sorooshian, K. Mitchell, and W. Emmerich, 2005: Evaluation and transferability of the Noah land surface model in semiarid environments. J. Hydromet., 6(1), 68-84.

Idso, S., 1981: A set of equations for the full spectrum and 8- and 14-micron and 10.5- to 12.5 thermal radiation from cloudless skies. Wat. Resour. Res., 17, 295-304.

International GEWEX Project Office, 2002: GSWP-2: The Second Global Soil Wetness Project Science and Implementation Plan. IGPO Publication Series No. 37, 65 pp.

Kopp, T.J. and R.B. Kiess, 1996: The Air Force Global Weather Central cloud analysis model. AMS 15th Conf. on Weather Analysis and Forecasting, Norfolk, VA, 220-222.

Koren, V., J. Schaake, K. Mitchell, Q.Y. Duan, F. Chen, and J.M. Baker, 1999: A parameterization of snowpack and frozen ground intended for NCEP weather and climate models. J. Geophys. Res., 104, 19569-19585.

Koster, R.D. and M.J. Suarez, 1996: Energy and Water Balance Calculations in the Mosaic LSM. NASA Technical Memorandum 104606, 9, 76 pp. 
Kumar, S.V., C.D. Peters-Lidard, Y. Tian, P.R. Houser, J. Geiger, S. Olden, L. Lighty, J.L. Eastman, B. Doty, P. Dirmeyer, J. Adams, K. Mitchell, E.F. Wood, and J. Sheffield, 2006: Land Information System-An interoperable framework for high resolution land surface modeling, Environ. Modelling and Software, 21, 1402-1415.

Lettenmaier, D., D. Lohmann, E.F. Wood, and X. Liang, 1996: PILPS-2c Workshop Report, Princeton Univ., Princeton, N. J., October 831.

Leuning, R., H.A. Cleugh, S.J. Zegelin, and D. Hughes, 2005: Carbon and water fluxes over a temperate Eucalyptus forest and a tropical wet/dry savanna in Australia: measurements and comparison with MODIS remote sensing estimates. Agricultural and Forest Meteorology, 129, 151-173.

Liang, X. and 28 co-authors, 1998: The Project for Intercomparison of Land-surface Parameterization Schemes (PILPS) phase 2(c) Red-Arkansas River basin experiment: 2. Spatial and temporal analysis of energy fluxes, Global and Planetary Change, 19, 137-159.

Liang, X. and J. Guo, 2003: Intercomparison of landsurface parameterization schemes: sensitivity of surface energy and water fluxes to model land characteristics. J. Hydrol., 279, 182-209.

Manabe, S., 1969: Climate and the Ocean Circulation 1. The Atmospheric Circulation and the Hydrology of the Earth's Surface. Monthly Weather Review, 97, 739-774.

Pitman, A.J., 1994: Assessing the sensitivity of a land-surface scheme to the parameter values using a single column model. J. Climate, 7, 1856-1869.

Pitman, A.J. and 25 co-authors, 1999a: Key results and implications from phase 1(c) of the Project for Intercomparison of Land-surface $\mathrm{Pa}$ rameterization Schemes. Climate Dynamics, 15, 673-684.

Pitman, A.J., M. Zhao, and C.E. Desborough, 1999b: Investigating the Sensitivity of a Land Surface Scheme's Simulation of Soil Wetness and
Evaporation to Spatial and Temporal Leaf Area Index Variability within the Global Soil Wetness Project. J Meteor. Soc. Jap., 77, 281290.

Reynolds, C.A., T.J. Jackson, and W.J. Rawls, 2000: Estimating soil water-holding capacities by linking the Food and Agriculture Organization soil map of the world with global pedon databases and continuous pedotransfer functions. Water Resources Research, 36(12), 3653-3662.

Rodell, M., P.R. Houser, U. Jambor, J. Gottschalck, K. Mitchell, C.-J. Meng, K. Arsenault, B. Cosgrove, J. Radakovich, M. Bosilovich, J.K. Entin, J.P. Walker, D. Lohmann, and D. Toll, 2004: The Global Land Data Assimilation System. Bull. Amer. Meteor. Soc., 85(3), 381-394.

Sellers, P.J., Y. Mintz, and A. Dalcher, 1986: A simple biosphere model ( $\mathrm{SiB})$ for use within general circulation models. J. Atmos. Sci., 43, 505-531.

Shapiro, R., 1987: A simple model for the calculation of the flux of direct and diffuse solar radiation through the atmosphere. AFGL-TR-87-0200, Air Force Geophysics Lab, Hanscom AFB, MA.

Wood, E. and 27 co-authors, 1998: The Project for Intercomparison of Land-surface Parameterization Schemes (PILPS) Phase 2(c) Red-Arkansas River basin experiment: 1. Experiment description and summary intercomparisons, Global and Planetary Change, 19, 115-135.

Xia, Y., J. Pitman, H.V. Gupta, M. Leplastrier, A. Henderson-Sellers, and L.A. Bastidas, 2002: Calibrating a land surface model of varying complexity using multicriteria methods and the Cabauw dataset. J. Hydromet., 3, 181-194.

Xia, Y., Z.-L. Yang, P.L. Stoffa, and M.K. Sen, 2004: Optical parameter and uncertainty estimation of a land surface model: sensitivity to parameter ranges and model complexities. Advances in Atmospheric Sciences, 22(1), 142-157.

Xie, P. and P.A. Arkin, 1997: Global Precipitation: A 17-year monthly analysis based on gauge observations, satellite estimates and numerical model outputs, Bull. Amer. Meteor. Soc., 78, 2539-2558. 